\title{
A REPORT ON A TEST OF MESTER'S " SPECIFIC" REACTION IN RHEUMATIC CASES
}

\section{BY W. S. C. COPEMAN AND W. STEWART}

THE need is urgent for a specific test which will differentiate cases of true rheumatism, of any type, from those which should not be placed in this category. As Messoloff" wrote, "what we need is a specific reaction similar to the tuberculin test or the Wassermann reaction, which could be used as an absolute criterion in the diagnosis of all rheumatic manifestations. Until then all work done on this disease is prone to the many pitfalls and subject to the many difficulties that the students of tuberculosis and syphilis had to contend with less than a generation ago."

Mester ${ }^{2}$ has recently claimed that he has found such a reaction, which depends upon the special sensitivity of rheumatic patients to salicylic acid.

His description of the test is as follows: The patients are resting and fasting. A count is made of the white blood cells, and after this count 1 c.c. of a 0.1 per cent. aqueous solution of salicylic acid is injected intradermally, forming five blebs of 0.2 c.c. each on the flexor aspect of the forearm, and after 30 minutes another white count is made. During this time the patient is forbidden to eat, drink, or make any effort. Nearly all rheumatic patients, acute, subacute or chronic, show after the injection a drop in the number of white cells after 30 minutes. The lowest figure regarded as positive was 15 per cent. below the level before injection, but diminutions as great as 50 to 70 per cent. were observed. The reaction appears to be positive in every kind of rheumatic infection-joints, heart, serous membranes, nerves, eyes, etc. In a series 98 per cent. of rheumatic cases gave a positive result, while all controls were negative.

Mester claimed that by the use of this test malingerers can be detected, and cases of arthritis which are not due to rheumatism -e.g., tuberculous or syphilitic - can be divided off, since the test is positive only in cases of rheumatic fever, subacute rheumatism and chronic rheumatoid arthritis. He points out, however, that the results of the test must be read in conjunction with the clinical findings, as is the case with all biological tests.

Professor Lenoch ${ }^{3}$ carried out this test in 140 cases, divided 
into two groups, in the first of which a positive result was to be expected and in the second of which the number of leucocytes was not.expected to be greatly changed.

The first group consisted of 43 cases of chronic rheumatic polyarthritis; 30 cases of secondary chronic polyarthritis; 2 convalescent from these diseases and free from symptoms; 3 cases of scapulo-humeral peri-arthritis; 5 cases of spondylarthritis ankylopoietica; and 5 cases of rheumatic (idiopathic) sciatica-a total of 88 cases. The second group consisted of 22 cases of spondyl-arthrosis deformans and osteo-arthrosis deformans, chiefly of the lower extremities; 1 case of static disturbances; 10 cases of gout; 2 cases of sequels of thrombophlebitis; 1 case of severe congenital dislocation of hip; 1 case of tuberculosis of the hip-joint; 6 cases of acute and subacute gonorrhœal polyarthritis; 1 case of sacralisation of the fifth lumbar vertebra; 3 cases of intermittent hydrarthrosis; 1 case of intermittent claudication from peripheral arterio-sclerosis; 1 case of chronic teno-synovitis of unknown origin; and 1 case of healed severe fracture of the pelvis.

Summing up the results of his investigation Lenoch stated that Mester's reaction is very often positive in rheumatic disease of the joints, and may even be positive in exceptional cases of diseases quite unconnected with rheumatism. "On the grounds of our experience in $\mathbf{1 4 0}$ cases, we regard this test as a probable addition to our methods of diagnosis of the so-called rheumatic diseases. Like most diagnostic aids this test is far from infallible, but it is of great value when it becomes necessary to decide whether an inflammatory condition of the joints is of rheumatic or other origin." He points out that it is negative, as claimed by Mester, in cases of degenerative arthritis (osteo-arthrosis). He ends with a warning against making a diagnosis of " rheumatic joint pains" or " myalgia " with the aid of this test.

Our own test was conducted on a series of 50 cases which were grouped as follows:

I. Rheumatic cases:

(a) Acute and subacute rheumatism, 13.

(b) Fibrositis, 5.

(c) Sciatica, 4.

(d) Rheumatoid arthritis, 1.

II. Osteo-arthritis, 1. 
III. Meningococcal septicæmia (simulating acute rheumatism), 5 .

IV. Acute tonsillitis, 1.

V. Subacute osteo-myelitis, 1.

VI. Control cases:

(a) Enuresis, 4.

(b) Gastric investigation cases, 13.

(c) The writers, 2.

All the cases were such as are admitted to the wards of a service hospital. The cases of acute and subacute rheumatism showed manifestations of active rheumatic disease. The results obtained are shown in Table I. The sedimentation rate is increased considerably.

A short summary of a few of these cases is given.

CASE 20.-Male, age 26, a member of an infantry regiment with 17 months' service. Illness had started with pain and swelling of left knee ; admitted to bed in a reception station; while there tonsillitis set in followed by quinsy; had a similar attack the previous winter, and he had suffered from frequent sore throats. On admission there was involvement of both knees. His temperature was 101 and pulse 80 .

Case 21.-Male, age 38, with 5 weeks' service. Illness started with severe pain in hips and shoulders after a few days' initial drill; this was followed by bronchitis, requiring confinement to bed. After 8 days in sick-bay pain and swelling set in in left knee and he was unable to move the joint. Repeated attacks of tonsillitis occurred in the past. On admission there was gross swelling of left knee with marked restriction of movements. The temperature was 101 and the pulse 100 . There was myocardial involvement. He had been an athlete (mile runner), and there was a strong family history of rheumatic disease.

CASE 28.-Male, age 38, with 7 months' service; a labourer in civil life. Illness started 12 days before admission with severe pain in the ankles and feet. He was unable to get about. Eight days later left wrist became involved. On admission temperature was 101 and pulse 100; both ankles and left wrist were much involved. Since 1934 he had had three attacks of acute rheumatism which seemed to have cleared up completely.

CASE 44.-Male, age 20, with 1 month's service. Admitted with pain and swelling of both knees, the left being slightly greater than the right. He had had 14 days' confinement to bed in a reception station, during which time there had also been swelling of right wrist, but this had gone down with complete recovery after a few days. The temperature after he arrived in the ward was 102 and the pulse 70.

CASE 18, which showed the greatest fall ( $-25 \cdot 7$ per cent.), was a male, age 36, with 4 days' service prior to illness. This illness started 16 days previously with a severe sore throat, severe pains in back and head, cold sweats and transient fainting attacks. The following day a rash appeared, at which time he was admitted to hospital. The rash was of scarlatiniform 


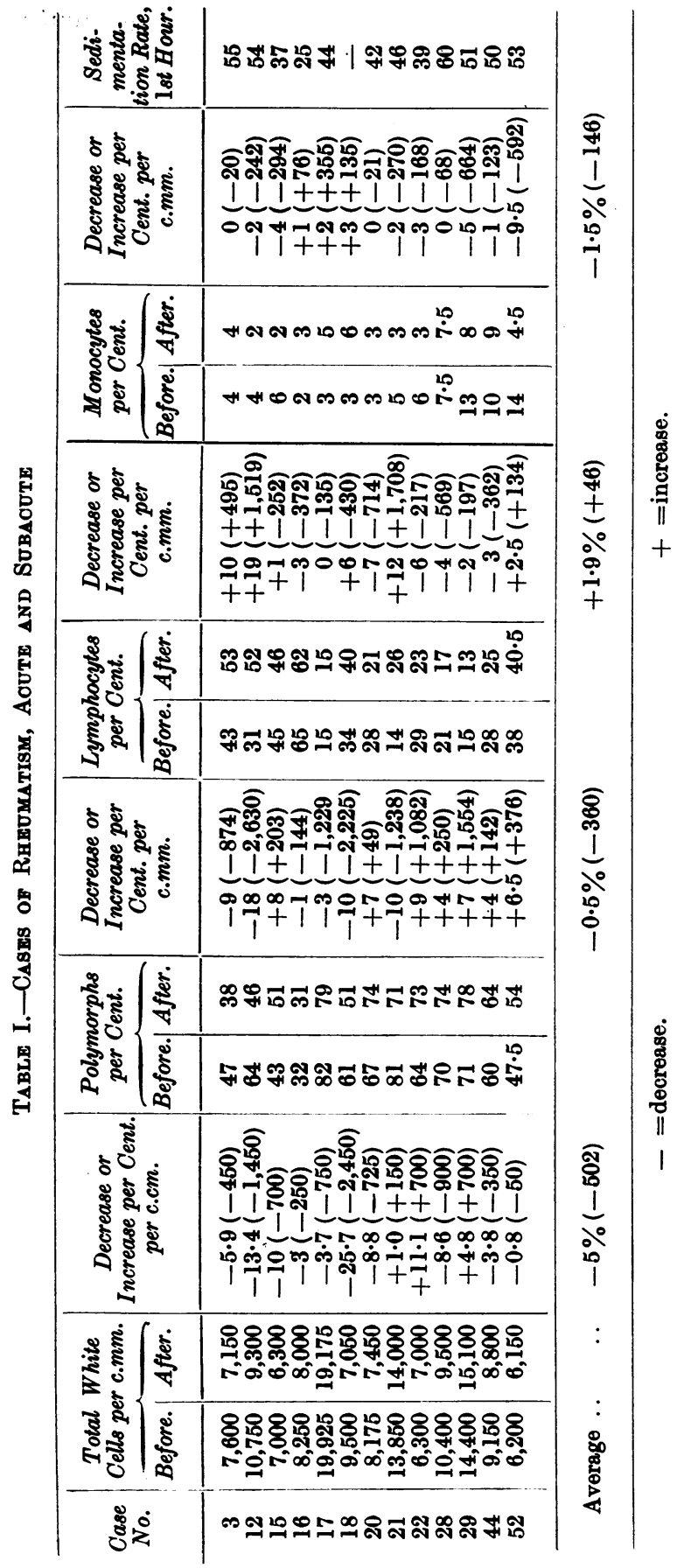




\section{MESTER'S “SPECIFIC" REACTION}

type, but he did not peel (in the opinion of the skin specialist, Major Betley, it was not scarlet fever). After 2 days quinsy developed; the day following there was severe pain in the left shoulder and left side of neck, and marked restriction of movement. Two days later marked improvement set in, the neck muscles being quite mobile, but there was some residual stiffness in the left shoulder. The temperature rose to 101 and the pulse to 120. The specimens of blood were taken during the attack in the neck and shoulder. He subsequently recovered completely.

Cases of fibrositis (the results are given in Table II):

Case 1.-A case of infective fibrositis in the muscles of the lower limbs following extraction of septic teeth. There was a strong rheumatic family history, and the patient had been a labourer in a show-ground where he was exposed to the weather.

CASE 5.-Fibrositis of the sacro-spinal and lower thoracic regions which cleared up with injection of local anæsthetics.

CASE 6. - There was pain in the muscles of the neck extending towards the right shoulder with myalgic areas along the borders of the trapezius muscle. He had had previous similar attacks at the same time of the year; these lasted 7 to. 15 days, and usually cleared up without specific treatment.

CASE 10.-Case of left-sided sciatica of peri-neuritic type.

Case 11.-Case of left lumbar fibrositis complicated by hyperthyroidism; there was mild exophthalmos and palpitation-the thyroid gland itself showed generalised enlargement.

Cases 23, 24, 25 and 26 were all cases of active fibrositis of the muscles in the lumbar region. All had tender areas in the regions involved and radiographic examinations showed no bony changes.

\section{Rheumatoid arthritis (Table II):}

Case 30 was a case of active rheumatoid arthritis in a female, age 42, with $2 \frac{1}{2}$ years' service. The lesion had started 18 months ago in the left knee followed by both hands. At present there is gross deformity in the hands, but no immobility in the wrist-joints. The sedimentation rate for the first hour was 27.

\section{Osteo-arthritis (Table III):}

Case 7 was a case of osteo-arthritis of the left sub-astragaloid joint in a regular soldier. He had had rheumatism in both feet for years, but his temperature and sedimentation rate were normal.

Cases of chronic meningococcal septicæmia (Table III).

Five cases of this condition were seen during the period of the test-that is, these cases were without meningeal involvement. All had positive blood-cultures and all were sent in as cases of "acute rheumatism." This type of case is an exceedingly important one for such a test on account of its close simulation of rheumatic conditions and the dramatic response to 


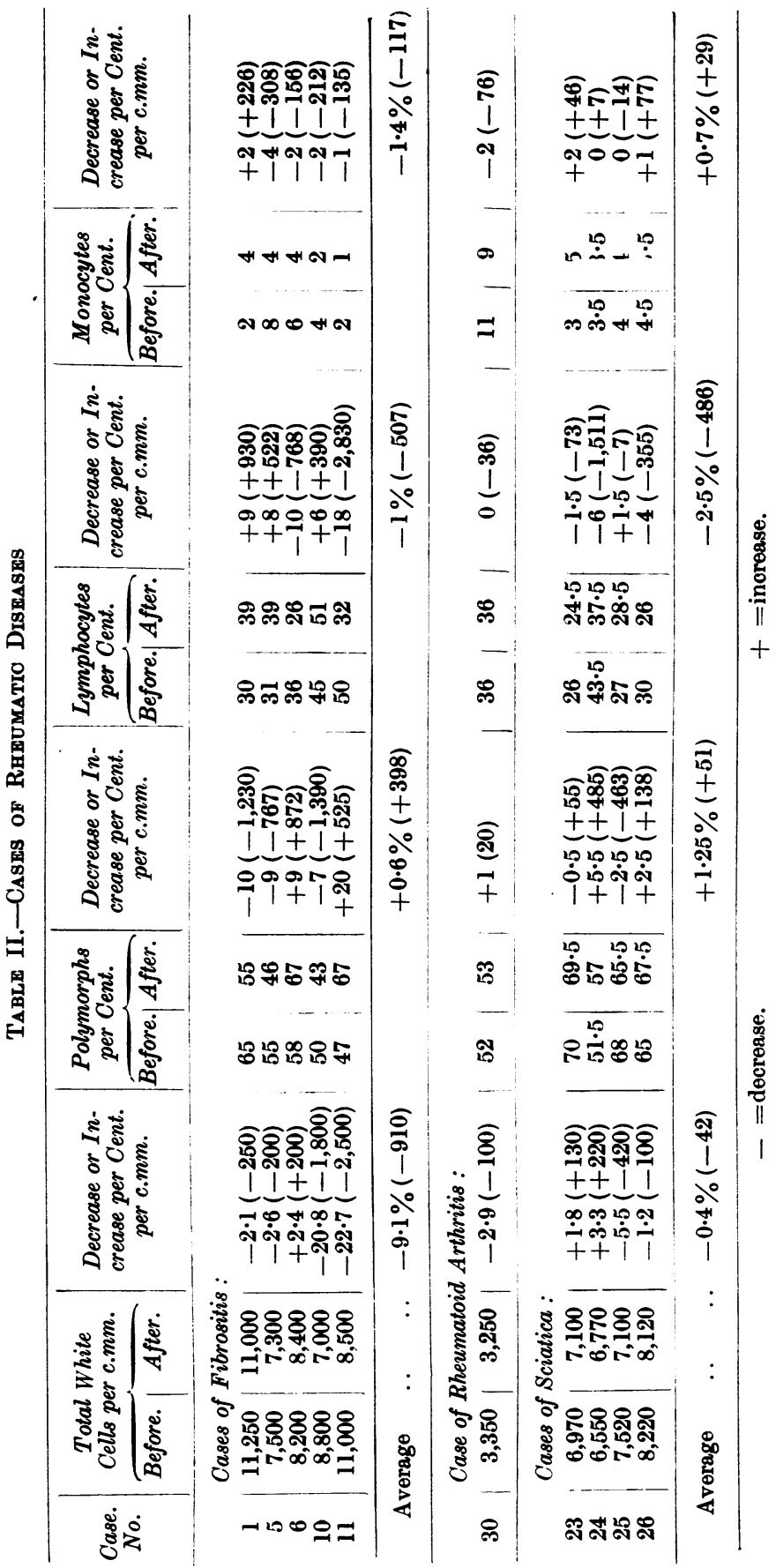


sulphanilamide therapy. It can only be differentiated with certainty from rheumatic conditions by blood cultures assisted by agglutination and complement-fixation tests. We believe that this condition is much more prevalent than is generally appreciated, and also that the "diplococcus rheumaticus" of Poynton and Paine which was found in some cases of acute rheumatism by these workers was really a meningococcus. 4 These cases are quite indistinguishable clinically from rheumatic conditions.

Kennedy ${ }^{5}$ in an interesting paper discusses four cases of chronic meningococcal septicæmia and stresses a possible specific relationship between a rash-like erythema nodosum and meningococcal infections. In his first case there is a history of illness extending over two years and four months. There were periodic temperature remissions from an evening temperature of $103^{\circ}$. $104^{\circ}$. Sweating was marked. There was a rash similar to erythema nodosum which appeared in crops and might disappear and reappear in the course of a day. A Gram-negative diplococcus was recovered from the blood-it was rather delicate and died before identification could be established. The patient subsequently died from a purulent meningitis, but cultures from the base of the brain were negative.

Case 2 appeared to be an atypical case of cerebro-spinal meningitis from the beginning in that the onset was a feeling of giddiness, headache, and pain at the back of the neck. Three days later the left foot swelled up.and spots appeared on the left leg. Salicylates were given. Fresh crops of spots kept recurring. A meningococcus was isolated from the blood. He subsequently developed gross meningeal symptoms and the cerebro-spinal fluid was turbid but negative on culture. He ultimately recovered.

Case 3 was a young soldier with rigors; a rash appeared first on the flexor surfaces of the arms and extended to the abdomen, chest and extremities; this rash in places was pustular. The diagnosis was erythema nodosum, and salicylates were given. The symptoms were strongly suggestive of acute rheumatic fever - severe generalised pains accompanied by a rise of temperatureand appeared to be relieved by salicylates. Blood cultures were negative.

Case 4 also appeared to be an atypical case of cerebro-spinal meningitis with onset of "wanted to vomit any minute." Two 
days later again "felt very sick and weak in the legs as if he might drop down"; there was a slight sore throat, headache across the forehead, aching of legs and arms, and papular spots over surface of tibia. He was put on salicylates and appeared to improve. Symptoms recurred sixteen days later, when a meningococcus was isolated from the blood stream. He subsequently recovered.

Cases 2 and 4, in the light of our experience during the epidemic of cerebro-spinal meningitis two years ago, we would put in the category of infection of the meninges. In such the meningeal symptoms may be slight and transient, yet the cerebrospinal fluid shows gross turbidity.

Case 3 is the story of a chronic meningococcal septicæmia such as we are meeting with at the present time, and in which we hoped this test would be of material assistance.

Stott and Copeman, ${ }^{6}$ with the assistance of bacteriology, have described this condition in the B.E.F. in France during 1940. These writers point out that a remarkable feature of these cases is the feeling of well-being even after an illness lasting many months.

This type of case may appear to respond to salicylates, but a similar result can and does occur with rest in bed without medication. It has been our experience lately that such cases of chronic meningococcal septicæmia are still prevalent in the absence of any increase in the number of cases of cerebro-spinal meningitis beyond the odd sporadic case.

Such cases are discussed here on account of their significance, beyond any reasonable doubt, in any consideration of the rheumatic diseases.

Acute tonsillitis :

Case 34 was a case of acute tonsillitis followed by acute cervical adenitis necessitating admission. He had had "rheumatic" pains in the past. The case was included on account of the association between infection of the tonsillar region and rheumatic manifestations. On admission his temperature was 101 but his pulse was normal.

Case 14 was a case of osteo-myelitis with a subacute flare-up of a chronic lesion of some 14 years' duration in the right tibia. A swelling appeared several times a year, discharged for a few days and then healed spontaneously. Seven days before the test he had been operated on. The temperature and pulse were slightly raised. Osteo-myelitis is a lesion which may and does simulate rheumatic conditions fairly closely, and a differential test would be of considerable value. 
As controls the authors and 13 patients were used, comprising cases of enuresis (4), internal derangement of knee-joint (2), and 7 dyspeptics. In the last group some were functional and in others a definite organic lesion was present. The results are grouped together and the average taken.

The counts were all taken with the patients in a fasting condition and at rest. Twenty-five of them were done at $\mathbf{1 2 . 0 0}$ hours-i.e., prior to the mid-day meal-and they had had no food since 07.00 hours of the same day. In the other 25 the specimens were taken at 17.00 hours, and in no case was the period since the last meal less than $4 \frac{1}{2}$ hours. Most of the cases were men-a feature inseparable from our present position-but females were also included as the opportunity occurred.

In addition to the total white cells differential counts were taken at the same time-200 white cells being counted. The figure for polymorphs, lymphocytes and monocytes are also given, as it was thought that if an appreciable change were found it would be interesting to see in which type of cell the change actually occurred.

In the cases of acute and subacute rheumatic conditions some showed an increase, others a decrease; the average of these 13 cases in the total white cells is a drop of -5 per cent. (502 per c.mm.); the differential figures in the polymorphs show a drop of -0.5 per cent. (360 per c.mm.); the lymphocytes an increase of +1.9 per cent. (46 per c.mm.), and the monocytes a drop of -1.5 per cent. (14.5 per c.mm.). With one exception none of the cases show a diminution of 15 per cent. 30 minutes after the injection. The exception (case 18) was undoubtedly a case of an active rheumatic lesion following streptococcal infection of the tonsillar region. Some of the cases show an increase (cases 21, 22 and 29).

In the fibrositis and sciatic groups similar results were foundsometimes an increase, other times a decrease. In only 2 cases was there a diminution of over 15 per cent.: (i) case 10 -a perineuritis of the sciatic nerve; and (ii) case 11-fibrositis in the region of the lumbar muscles.

In the cases suffering from meningococcal infections without meningeal involvement a similar result was obtained-sometimes an increase, sometimes a decrease. The case of acute tonsillitisa lesion often associated with the rheumatic conditions-showed 
a negative result. The control cases gave similar findingssimilar in their inconsistency.

It is to be noted that the greatest diminution $(-28.9$ per cent.) (case 7) occurred in a non-rheumatic condition.

The total white cell count may vary considerably during the daytime in the normal diurnal tides, and this could quite easily be a factor in such a test. The personal factor also comes inthe difference of a few per cent. is not to be unexpected.

\section{Conchusions}

Such a test in its results requires to be specific and consistent if it is to be of value. The findings in this series, which, though small in numbers, includes cases of typical acute rheumatic disease, do not confirm those of the original investigator, and the test, therefore, does not help in the diagnosis of rheumatic diseases. We have found it to be negative in cases of frank rheumatic disease and positive in cases of non-rheumatic conditions, and we submit that it is not a specific one for rheumatic diseases; this confirms Professor Lenoch's warning against making a diagnosis of "rheumatic joint pains" or "myalgia" with the aid of the test.

It is a pleasure to us to record our appreciation of the cooperation of Colonel H. E. Edwards, R.A.M.C., and of the assistance of Sergeant T. Bury, R.A.M.C.

\section{REFERENCES}

1. Messoloff, C. R.: Medical Life (Philadelphia), January, 1930.

2. Mester, A. J.: Annals of the Rheumatic Diseases, vol. ii, No. 4, December, 1941, pp. 266-7.

3. LENOCH, F.: Wiener Klin. Woch., vol. li, 1938, pp. 363-6.

4. Copeman, W. S. C., and Stewart, W.: Lancet, vol. cexlii, May 16, 1942 , p. 603.

5. KENNEDY, J. C.: Journ. R.A.M.C., vol. xlvii, 1926, p. 6.

6. Stott, A. W., and Copeman, W. S. C.: Lancet, vol. cexxxviii, 1930, p. 1116. 